\title{
Enhancement of Master Students' Professional Preparation on the Basis of Modern Technologies
}

\author{
E. E. Seydakhmetov ${ }^{1}$, B. M. Baimukhanbetov ${ }^{1}$, S. B. Aknazarov ${ }^{1}$, K. I. Alshynbayev ${ }^{2}$ \& S. T. Nyshanova ${ }^{1}$ \\ ${ }^{1}$ H. A. Yassawi International Kazakh-Turkish University, Kazakhstan \\ ${ }^{2}$ Regional Social-Innovative University, Kazakhstan \\ Correspondence: S. T. Nyshanova, H. A. Yassawi International Kazakh-Turkish University, Kazakhstan. E-mail: \\ saltanur@mail.ru
}

Received: February 27, 2015 Accepted: March 31, 2015 Online Published: July 28, 2015

doi:10.5539/ies.v8n8p109 URL: http://dx.doi.org/10.5539/ies.v8n8p109

\begin{abstract}
In the period of passing to the world civilization and democratic tradition, the Republic of Kazakhstan pays great importance to the general values heritage of human society stored/perpetuated over the centuries and the enhancement of specialists' professional preparations through forming healthy life style habits on the basis of modern technologies and developing physical-upbringing on the spiritual and moral base. This problem was raised as one of the actual tasks of the education system in the program "Kazakhstan-2030" of the President N. Nazarbayev, 2014; in the law of the Republic of Kazakhstan "About knowledge", 2008; and "The State Program of the education development in the Republic of Kazakhstan for 2011-2020”, 2010.

The investigation of physical upbringing, modern technology and advances of experiments in a close connection with of the national and general human values laws is one of the obligations of the professional pedagogy science resulted from the requirements of the modern society. Considering the essence of physical upbringing according to the requirements of modern society is defined by recognizing a person not as a successful offspring of the environment in which he lives, but also as a subject distinguished by his physical culture and moral relationships. Considerable changes in the society are bringing some changes to person's purposes, manner of life and behavior and even in him as a subject. Furthermore, the literacy in the society, comprehensive investigations on the nature, essence and functions of physical culture and spiritual values and the necessity of considering the problem of using modern technology in the system of preparing master-students in the scientific pedagogical direction define the importance of our research theme.
\end{abstract}

Keywords: professional preparation, modern technology, master students

\section{Actuality of the Research}

Taking into account the historical feature of interrelation and interconnection of the development of science, techniques, culture and education and also as the results of theoretical investigations studying and systemizing the advanced experiences show, the significance of analyzing theoretical and methodical problems objectively in the qualitative preparation of specialists on teaching pupils leading healthy lifestyle has been identified.

Alongside with promoting the health of young people, a physical upbringing system in the modern education institutions is based on the comprehensive development of biological and psychological necessities and the enhancement of an active position and benevolent relationships in personality. Functioning as a scientific and teaching subject, this important method is closely related to the teaching system in higher education institutions implementing the preparation of master-students in the pedagogical direction in the field of physical training and sport.

The scientists who devoted their investigations to the separate social problems of physical culture and sport were Tanikeev (1998), Stoliyarov (1997), Koshaev (1998) and others.

The introduction of modern technologies in all fields of human activity has clarified the new requirements to the education system. Analyses on the scientific literatures devoted to investigating problems about informatizing the education system (Richmond, 2014; Albastroiu, Felea, \& Vasiliu, 2014; Rodzvilla, 2015; Jin \& Bridges, 2014; Daniyarov, Bazarbaev, Myrzakhanova, \& Nyshanova, 2012; Uzakbaeva, Niyazova, Berdi, Baimukhanbetov, \& Seydakhmetov, 2013; Nyshanova, Baimukhanbetov, Abdugapparova, \& Mukhamedzhanov, 2014 and etc.) show 
that teaching content, methods, environments, teaching forms, functions, psychological and pedagogical features of subjects taught in higher education system will obtain new structures.

Enhancement ways of master-students' preparation in higher education institutions were comprehensively considered in the works of A. Badulescu, D. Badulescu, Bac, and Sipos-Gug (2014), Mirzaee and Hasrati (2014), Rienties, Luchoomun, and Tempelaar (2014), Yermentaeyeva, Turgunbayeva, Bazarbekova, Nurtayev, and Bekzhanova (2014), Berkimbaev, Nyshanova, Kerimbaeva, and Meirbekova (2012); Uzakbaeva, Baimukhanbetov, Berkimbaev, Mukhamedzhanov, and Pralieva (2013), Jandildinov, Baimukhanbetov, Aknazarov, and Uaidullakyzy (2013), Korkmaz, Baimukhanbetov, Abdillayev, Aknazarov, and Nyshanova (2014).

The civilization of our country requires a comprehensive development of an individual through the acquisition of high obligations, creative and organizing abilities, qualitative theoretical preparations and methodical qualifications, appropriate methods of teaching and upbringing and directs them to work productively.

The increase of requirements for the knowledge quality of master-students graduating higher education institutions is the base of scientific-technical development that brings changes to the education process. Nowadays, the enhancement of obtaining higher quality in activity and making influential decisions are impossible without acquiring methods of using modern technologies.

In the present time, modern technologies are widely used in the industry, enterprises and in the activities of filing down documents; the activity field that it involves is greatly widened. Due to the stable increase of volume and complexity of processing information, new types of describing it are demanded in the society.

\section{Methods of the Research}

Using modern technologies in enhancing scientific pedagogical preparation of specialists, namely master-students in the field of physical training and sport is one of the actual requirements of informational society for higher education institutions. Specialists who are quickly adjusted appropriate to the labour content and capable of acquiring new knowledge and skills are the basic information society needs.

The use of modern technologies helps to develop master-students' scientific cognition, thinking opportunities and to enhance their professional preparation. On the basis of using modern technologies in teaching process, master-students learn scientific cognitive methods as modern formulating and modeling. Modern technologies provide opportunities for developing formal-logical and systematic forms of master students' thinking and acquiring innovative methods of scientific cognition.

Through a comprehensive study on the requirements for knowledge quality of specialists of physical training and sport, we have analyzed the activities which create opportunities for making appropriate conditions to form professional important qualities of master-students via the use of modern technologies.

To our viewpoint, in solving professional problems, a direct investigation should be conducted on the subject conformed to acquiring skills of working with computers. Teaching basic modern technologies is the base of forming computer information systems at any complexity. The standard office information technologies of «MS Office», the program product of the widespread firm Microsoft, can be the basic information technologies.

The development of applied program provision market and powerful set infrastructure was the precondition of moving from investigating applied programs in teaching modern technologies to studying a special programs packet in a professional direction.

\section{The Results of the Research}

Our practical experiment ensures an introduction of our conception regulations, teaching programs and teaching-methodical equipment worked out for the preparation of master-students in the field of "Physical training and sport" in experience. During the practical-experiment, the works of Avasenov, Neiman, Kalanov, Омирбаев and others were used in conducting the works of measuring teaching results.

The tasks for the practical experiment:

1) To make the structure of teaching process appropraite through using modern technologies in teaching master-students of the specialty "Physical training and sport";

2) To enhance methodical system of teaching master-students of the specialty "Physical training and sport" through using modern technologies and to put the developed system into practice;

3)To process the result of the practical experiment work statistically and mathematically;

With a view to conducting practical experimental check on the correctness of the research prediction, 
experiments were conducted in K. A. Yassawi International Kazakh-Turkish University and Regional Social-Innovative University.

46 master-students were involved in the practical experiment work.

Different variants of conducting lessons were used. Using induction and deduction simultaneously was effective as the methods of recognizing a pedagogical phenomenon. Through revealing the importance and essence of each variant, the transfer from every variant (every state) to a general state was implemented.

In the result of questionnaire conducted repeatedly in the cheaking stage of the practical-experiment work, the degree of knowledge and proficiency on professional subjects of master-students was defined. 19 of 46 involved master-students were in an experiment group, while 27 were in a control group.

The practical experiment works consisted of 3 stages (defining, forming, controlling).

For the purpose of designating the concrete state of the issue under consideration during the defining experiment, on the basis of making analyses on the programs and teaching, teaching-methodical equipment of the subjects "Computer technologies in the field of physical training and sport" and "Modern innovative technologies in the field of physical training and sport", the degree of these subjects providing students' capacities of implementing their theoretical and practical knowledge based on modern technologies was identified. At the same time, the degree of acquiring subjects based on modern technologies set in the state standard of the first academic semester of magistracy was analyzed.

In the second stage of the defining experiment, a questionnaire and interview were conducted with a view to check the degree of using modern technologies of master-students graduating the higher education institution.

Therefore, in the defining stage, the decisions of the following tasks were searched to designate the actual state of teaching-upbringing processes and an initial degree of this preparation in the above mentioned higher education institutions: to define the issue and purpose of the experiment investigation; to select the object and theme of the experiment work and to base conducting it theoretically; to conclude the experiment prediction; to define the number of master-students (an experiment group and in control group); to define work forms conducted during the experiment; to select necessary methodologies to define the initial preparation degree of master-students in acquiring modern technologies and to check its efficiency; to prepare a didactic complex due to the enhancement of preparation degree of master-students on subjects based on modern technologies, to define changes and pedagogical influences in preparations of master-students as a result of the experiment.

The quantitative and qualitative analyses conducted on master-students' knowledge obtained on the subjects based on modern technologies defined insufficiencies of the content and methods in compulsory and scientific pedagogical teaching fixed in the state standard and showed the necessity of enhancing them. The control carried out on defining the concrete state of master-students' knowledge and skills acquired through subjects based on modern technologies showed low degree of their preparation. The programs and teaching methodological tools used in higher education institutions consider insufficiently the theoretical and methodological bases of subjects based on modern technologies and show master-students' knowledge and proficiency insufficiency on subjects based on modern technologies. To be exact:

- A clear, systemic and purposeful succession of teaching subjects that ensure forming master-students' abilities using modern technology tools and program equipment was not made;

- Interrelation and connection between subjects based on modern technologies and proficiency subjects were not implemented;

- The content (programs and teaching materials) of special courses specialized to develop teaching subjects based on modern technologies and the courses conducted according to the selection of master-students were not identified sufficiently.

Therefore, alongside with a comprehensive acquisition of knowledge, teachers of higher education institutions should also improve their teaching methodologies in order to provide master-students' knowledge and skills to use modern technologies and to form their proficiencies of using modern technologies in their professional pedagogical functions.

The results obtained in the defining stage was the base for forming research predictions, developing master-students' knowledge on the subjects based on modern technologies and enhancing the methodological bases of preparing specialists in the field of physical training and sport.

In this stage, literatures appropriate to the set purpose was discussed, generalizing methods including theoretical and practical methods are used as a result of analysis: to make analysis on literatures specialized on conducting 
subjects based on psychological and pedagogical literatures, methodological and modern technologies, to collect and generalize experiences, to make analysis on experiences collected during the period of working in higher education institution, a questionnaire and an interview with teachers.

In the questionnaire, the methods of asking questions aimed at getting written answers and personal talk were used. The purpose of conducting this questionnaire is to identify the importance of implementing the usage of modern technologies in forming master-students' professional competencies and their impact on knowledge degree of master-students.

Due to the set tasks, conducting the questionnaire was divided into two periods:

1) The questionnaire aimed at identifying the quality of using modern technologies of master-students was taken in the beginning of the investigation.

2) The questionnaire aimed at defining master-students' professional knowledge formed through using modern technologies was taken at the end of investigation.

Alongside with an oral method of the questionnaire, a talk, an interview and a written questionnaire were conducted.

With a view to change the pedagogical process in the forming stage of the experiment, a description of master students' activity and a conception of preparing master-students and its methodological base were formed due to psychological, pedagogical and methodical results. Through the analysis on theoretical and practical works about teaching master-students by using modern technologies, a lack of preparation system aimed at forming skills to use modern technologies in their professional function and the necessity of forming this system were identified.

Therefore, a practical experiment work was organized and the following tasks were set in the forming period:

- To select the content of the practical experiment work;

- To identify the efficiency of methodological system introduced into the teaching process;

- To collect information about changes in the preparation degree of master-students through preliminary control works;

- To search the ways of defining the difficulties and insufficiencies in the practical and experiment process.

Due to the conducted analysis work, the necessity of introducing methodological suggessions directed to promote master-students' proficiencies of using modern technologies via deepening and extending their skills of using innovative modern technologies was clarified. On this purpose, a task was set to increase the methodological preparation to a new degree.

In the controlling stage (teaching, correcting) of the practical-experiment work, a control was conducted on teaching efficiency on the basis of methodical system worked out through the subjects based on modern technologies. The degree of teaching experimental group of master-students modern technologies was clarified. A forming experiment was carried out with a view to check the method of using modern technologies in the preparation of master-students in practice and to convince the correctness of scientific prediction of the investigation. At the end of the experiment, concluding works on quantitative and qualitative analysis results were carried out through comparing the initial and the last degrees of acquiring modern technologies used in pedagogical field of the experimental group.

A stageous control was carried out on the methodological efficiency of preparing master-students on scientific pedagogical base through modern technologies. Therefore, the tasks undertaken in the controlling period are as following:

- To analyze the experiment information obtained in the process of the practical experimental work;

- To check these materials in comparison with the purpose, tasks and predictions of the investigation;

- To process the experiment results mathematically and statistically;

- To systemize and process the last changes and advantages in master-students' professsional preparation degree on modern technology;

- To give a description on interrelation peculiarities between master-students and teachers- professors.

The method of preparing master-students on the basis of scientific pedagogical base and modern technologies was carried out on a special methodological system base (programs, teaching-methodical complexes, tools and suggessions). 
The effectiveness of the methodical system suggested during teaching was conducted through a complex monitoring. They are: to clarify knowledge degree pre and post teaching master-students on a new methodical system; master-students' ability of doing tests of subject materials based on modern technologies; an ability of setting targets to acquire skills of using modern technologies in their professional functions; an ability of forming tasks appropriate to the set tasks through taking into consideration the content peculiarities of the theme under consideration; an awareness of multimedia technologies.

The master-students of the first and second courses involved in the practical experimental work. A teaching material was conducted on the basis of a traditional method in one of the control and experimental groups and in the other group it was carried out through using authorial teaching-methodical equipment; that is, lessons were conducted on an authorial method.

In K. A. Yassawi International Kazakh-Turkish University, a program of an automatic testing system specialized to check and monitor master-students' knowledge appropriate to the requirements of the present day was prepared on the suggested course program. With a view to check the correctness of the experimental teaching, the probability method $\chi$ was used to compare a comprehension degree of teaching material of master-students in the control and experimental groups. Therefore, control tests of master-students were taken and a qualitative analysis on the test result was carried out.

The examples of tasks prepared to check master-students' degree of using modern technologies in resolving teaching and scientific pedagogical obligations were shown. This kind of tasks were given and checked in each year of teaching.

The exponents of enhancing future teachers' preparation on subjects based on modern technologies through elective course content were taken into consideration in the following ways:

1) An ability to solve scientific pedagogical activity on the innovative viewpoint through acquiring subjects based on modern technologies.

2) An acquisition of solving pedagogical problems via the use of modern technologies.

3) An ability to use knowledge and skills acquired through modern technologies in identifying the ways of setting pedagogical problems and solve them.

4) An ability to use multimedia technologies.

The problem of finding the effectiveness of the practical experimental work is related to the problem of measures and degrees. In the theory and practice of pedagogical education, there are general requirements that are set to find and base measures. They are: to show general regulations of forming an individual with the help of measures; to establish relations between all components of a system investigated with the help of measures; of qualitative exponents and quantitative exponents; united index of qualitative exponents and quantitative exponents.

Different methods of scientific pedagogical investigations were used in the process of the practiocal experimental work. Their use was directed to gain methodological, theoretical and didactic results.

To identify dependent and independent changes during the experiment, a theoretical analysis, questionnaire and diagnostic methods, analysis on programs of subjects conducted via the use of modern technologies, analysis on activity products of teachers-professors and master-students, a comprehensive acquintance with modern technologies of computer laboratories, defining, forming and monitoring pedagogical experiments and mathematical statistics methods were used.

The experiment was carried out in the definite teaching process. Grading was implemented through analyzing master-students activities in the classes of subjects based on using modern technologies. With a view to identify qualitative exponents of the pedagogical experiment results, the following mathematical statistics methods were used:

1) $\mathrm{P}$ is a coefficient of defining the completeness of implementing activity

$$
P=\frac{\sum_{i=1}^{n} n_{i}}{n N}
$$

here $n$ is the number of activities which are done mostly;

$n_{i}$ is the number of an activity done correctly by a master-student; 
$N$ is the number of master-students involved in doing the task;

$\sum n_{i}$-is the number of activities done correctly by all master-students.

2) The coefficient of forming master-students' professional knowledge and proficiency successfully in the teaching process was defined by the following formula:

$$
\beta=\frac{P_{2}}{P_{1}}
$$

Here, $P_{l}$ is a completeness coefficient of completing activities in the beginning of the definite teaching period, while $P_{2}$ is a completeness coefficient of completing activities at the end of the definite teaching period.

3) With a view to identify a successful completion of some elements of activities, a percentage quantity of the number of master-students completing these activities was defined with regard to the numbers of master-students completing the activities successfully;

4) Teachers and professors of the department "Physical training and sport", who conducted practical classes for master- students and supervised their scientific practice clarified an analytical rate of implementing an interdisciplinary relation of teaching materials of proficiency subjects and the subjects based on modern technologies and the rate of master-students' acquisition of professional activity elements. Comparing these rates gave the opportunity to designate the straightforwardness of evaluating master-students' preparation degree. For this purpose, $(K)$ correlation coefficient denoting dependence outline between these rates was defined. Since the division regulation of a measuring quantity was not identified, in most cases, measuring was implemented via a regulating scale (level, scoring rating). Therefore, Spirman's ranging correlation coefficient was used as the correlation coefficient:

$$
K_{s}=1-\frac{\sigma \sum_{i=1}^{N} R_{i}^{2}}{N\left(N^{2}-1\right)}
$$

Here, $\mathrm{R}$ is a quantifier's rang, while $\mathrm{N}$ is a number of choosing.

5) A formula of defining $X$ statistical average meaning was used to define an average number:

$$
X=\frac{\sum_{i=1}^{N} f x_{i}}{N}
$$

Here, $x_{i}$ is the quantity of a separate member; $f$ is an appearance frequency of separate quantifier; $N$ is the number of them.

6) (t) criterion was used to check the straightforwardness of the acquired knowledge:

$$
t=\frac{x \sqrt{N-1}}{\delta}
$$

Here, $\delta$ is a standard deflection; $N$ is the selecting number.

7) with a view to identify a correct boundary of marks average meaning, a standard mistake of an average meaning was defined according to this formula:

$$
m=\sigma / \sqrt{N}
$$

Mathematical calculations were made with the help of program packets on information statistics processing.

Master-students' interest in acquiring modern technologies at a sufficient degree was observed, but a low degree of their knowledge in using modern technologies was defined.

As a result of the questionnaire, approximately half of master-students (48\%) did not reject that they had felt a feeling of worry in the process of working with modern technologies. At the same time, master-students (76\%) involved in the questionnaire confessed that computers were used as domestic needs and playing equipment; $78 \%$ use an e-mail in the Internet and make great use of digital technologies in processing pictures and etc. 
However, $40 \%$ use any certain modern technology in learning activities. This information shows the low degree of motifs, knowledge, proficiency and interest in using modern technologies in learning process.

Table 1. Enhancement exponent of master-students' scientific pedagogical preparation through using modern technologies

\begin{tabular}{|c|c|c|c|c|c|c|c|}
\hline \multirow{2}{*}{ Components } & \multirow{2}{*}{$\begin{array}{c}\text { Work } \\
\text { period }\end{array}$} & \multicolumn{2}{|c|}{ High } & \multicolumn{2}{|c|}{ Medium } & \multicolumn{2}{|c|}{ Low } \\
\hline & & EG & CG & EG & CG & EG & $\mathrm{CG}$ \\
\hline \multirow{2}{*}{$\begin{array}{ll}\text { Motivational } & \text { (motivation } \\
\text { degree) }\end{array}$} & Start & - & - & 34.64 & 38.39 & 46.57 & 43.33 \\
\hline & Finish & 15.86 & - & 23.8 & 49.46 & - & 30.11 \\
\hline \multirow{2}{*}{$\begin{array}{l}\text { Gnostic (knowledge degree } \\
\text { on modern technologies } \\
\text { bases) }\end{array}$} & Start & - & - & 32.65 & 49.46 & 50.54 & 31.33 \\
\hline & Finish & 12.87 & - & 27.61 & 48.39 & - & 29.03 \\
\hline \multirow{2}{*}{$\begin{array}{l}\text { Technological (a proficiency } \\
\text { degree of using modern } \\
\text { technologies) }\end{array}$} & Start & - & - & 34.15 & 51.61 & 46.11 & 32.26 \\
\hline & Finish & 12.97 & - & 28.69 & 50.53 & - & 27.96 \\
\hline
\end{tabular}

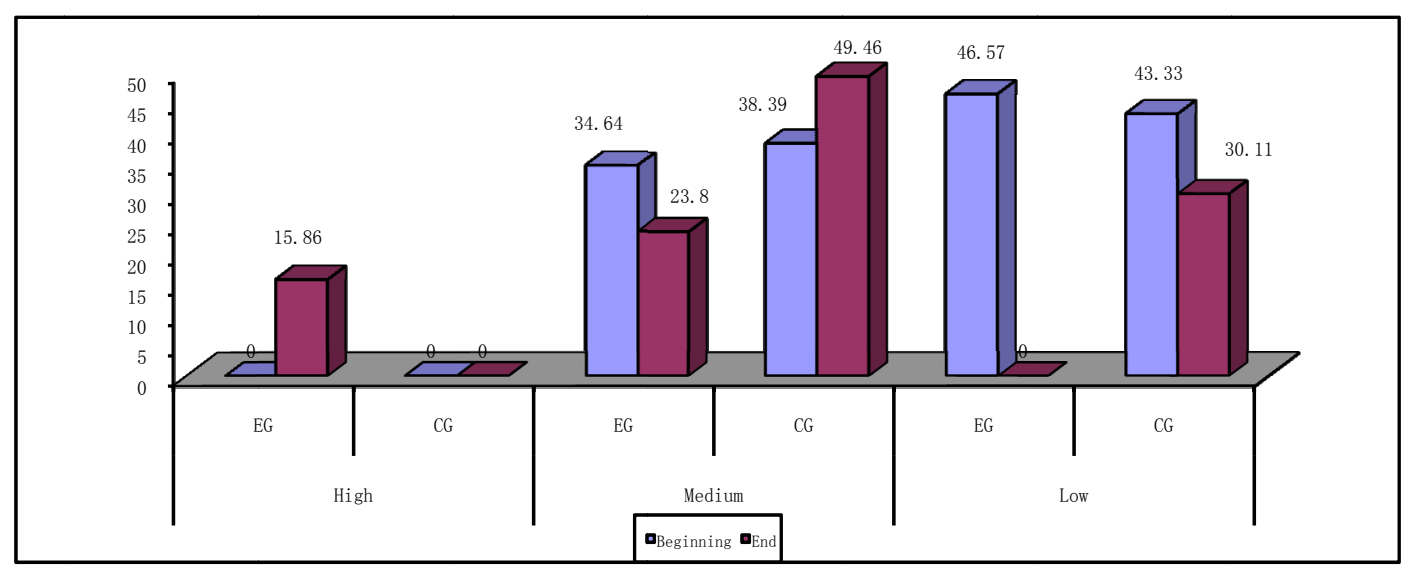

Figure 1. Enhancement exponent (motivational) of master-students' scientific pedagogical preparation through using modern technologies

The motivational criterion was evaluated by the questionnaire results. The results was measured by 5 score scale, 1-2 scores are low levels, 3-4 scores are medium levels and 5 is the highest level of the motivation.

Gnostic criterion was measured by a computer test. During the test, 100 score scale was used in completing tasks. Here, 60-70 scores are low levels, 70-90 scores are medium and 90-100 are the highest knowledge levels.

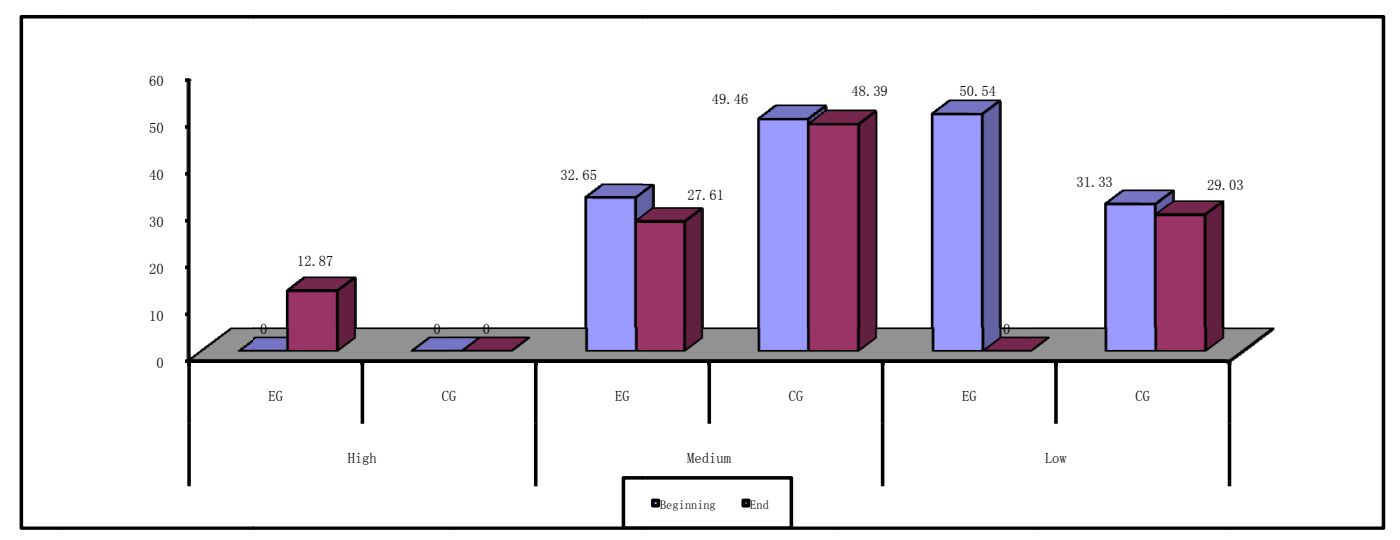


Figure 2. Enhancement exponent (gnostic) of master-students' scientific pedagogical preparation through using modern technologies

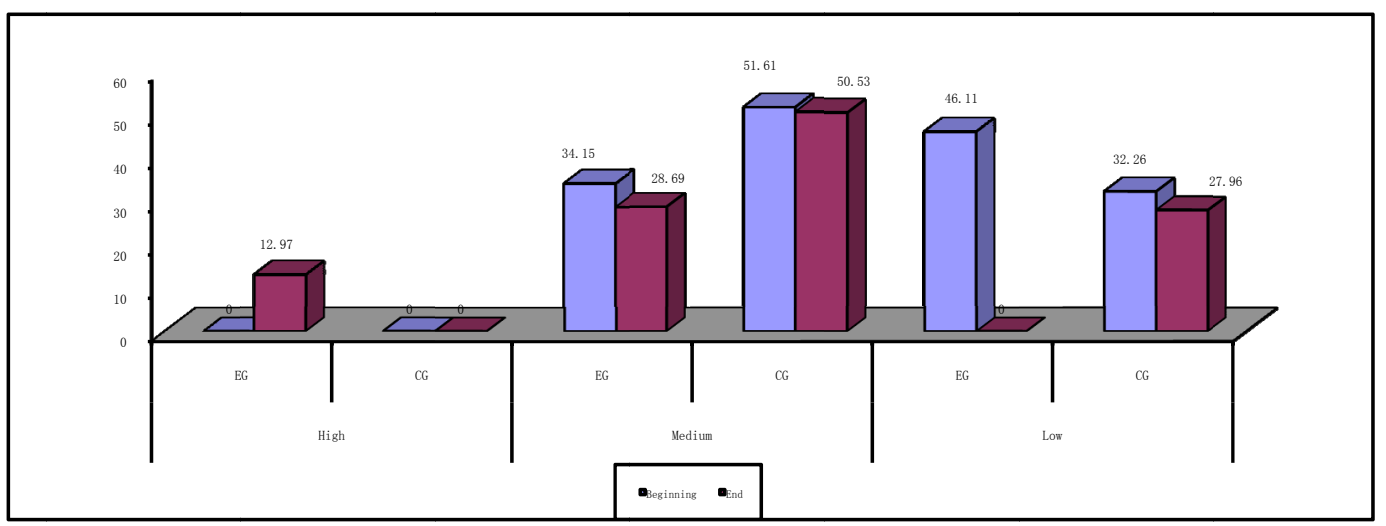

Figure 3. Enhancement exponent (technological) of master-students' scientific pedagogical preparation through using modern technologies

As a technological criterion, a qualification of using modern technologies practically was evaluated. Master-students' abilities of making correct decisions, their accurateness, complexity and individual activities are their practical qualifications.

Thus, the pedagogical experiment results proved the correctness of our initial predictions. The tasks set as a result of the pedagogical experiment were completely solved and an adequet conclusion was made.

The comparison on the control work results of the experiment department of the course showing scientific pedagogical directions and other departments show good acquisition of the experimental materials by the master-students.

The opinions gained in the result of conducting questionnaire for master-students and in the process of the talk with teachers proved an efficiency of master-students' control works, the results of their project works and teaching-methodological tools.

Thus, the prediction of the pedagogical investigation was proved in the result of the practical experiment. This gave an opportunity to realize a teaching method based on the modern technologies through analyzing professional analysis on teaching content and the method of preparing master-students to solve the problems connected with the use of modern technologies.

\section{Conclusion}

The following conclusion can be made due to the results of suggested investigation work:

1) The experiment aimed at defining a theoretical methodology of using modern technologies in teaching master-students gave the opportunity to identify philosophical, psychological, pedagogical and methodological literatures, to analyze fundamental scientific investigation works and investigation directions of the problem related to enhancing the professional qualifications on modern technologies of specialists in the field of "Physical training and sport";

2) The teaching content and methodological system of the compulsory and proficiency subjects due to the changes resulted from the introduction of modern technologies were enhanced through making the elective course program and suggesting a teaching methodology of the course;

3) During the experiment aimed at the enhancement of using modern technologies in the scientific pedagogical preparation of master-students teaching methodological tools were introduced in the teaching process of higher education institution.

4) In the result of the practical experiment, the ways of enhancing methodological system of teaching master-students through using modern technologies were proved as one of the way of promoting professional knowledge of master-students. Moreover, the stored theoretical and methodological materials prove the succession of the suggested investigation prediction.

The following suggestions can be offered according to the investigation results: 
- In the teaching process, subjects like «Computer technologies in the field of physical training and sport», «Modern innovative technologies in the field of physical training and sport» should be increased quantatively since they deepen master-students knowledge on modern technologies, form practical knowledge and skills, activate the use of modern technologies in their professional functions, adjust them on scientific investigation works, develop their thinking abilities, form and enhance them professionally.

- Teaching hours (credits) on the compulsory and proficiency subjects based on modern technologies in the academic plan of the specialty "Physical training and sport" should be increased;

- The level of master-students in using modern technologies should be increased, teaching programs, electronic books and electronic teaching manuals, informational technologies should be introduced in the teaching process to develop master-students' competitiveness to acquire the innovative technologies and to develop their creativity and investigation preparations.

As the problem under consideration is complex and new, it is early to say that it has been solved thoroughly. In the future, independent investigations should be conducted on teaching methodology, complex problems related to professional activities, mathematical computer modeling problems with a view to prepare master-students in the scientific pedagogical direction.

\section{References}

Albastroiu, I., Felea, M., \& Vasiliu, C. (2014). Geographic information system-modern teaching method in business administration. Amfiteatru economic, 16(37), 770-783.

Avasenov, V. S. (2002). Definition, subject and main functions of pedagogical diagnostics. Pedagogical diagnostics, 1, 41-44.

Badulescu, A., Badulescu, D., Bac, D., \& Sipos-Gug, S. (2014). Attitudes and intentions of business master students towards sustainable tourism and entrepreneurship. Amfiteatru Economic, 16(8), 1110-1124.

Berkimbaev, K. M., Nyshanova, S., Kerimbaeva, B., \& Meirbekova, G. (2012). Formation of Informational competence of future specialists. New Educational Review, 30(4), 271-281.

Daniyarov, T., Bazarbaev, K., Myrzakhanova, A., \& Nyshanova, S. (2012). The peculiarities of forming rural school students' healthy living skills after school and extracurricular work by the use of information innovative technology. International Education Study, 90-98.

Jandildinov, M., Baimukhanbetov, B., Aknazarov, S., \& Uaidullakyzy, E. (2013). Evaluation Experience of Competence of the Future Specialist. 2nd Cyprus International Conference on Educational Research, CY-ICER 2013. Procedia-Social and Behavioral Sciences, 89, 932-938.

Jin, J., \& Bridges, S. M. (2014). Educational Technologies in Problem-Based Learning in Health Sciences Education: A Systematic Review. Journal of medical internet research, 16(12), 142-154.

Kalanov, Sh. M., \& Omirbayev, S. M. (2003). On the introduction of credit system in higher education institutions of the Republic of Kazakhstan. Problems of the introduction of a credit system in higher professional education: Proceedings of the All-Russian meeting of 23/04/03, Moscow. Publishing House of the People's Friendship University.

Korkmaz, M., Baimukhanbetov, B. M., Abdillayev, A. K., Aknazarov, S. B., \& Nyshanova, S. T. (2014). Teacher and Classroom Context Effects on Academic Achievement of Primary School Students. Life Science Journal, 11(1s), 233-240.

Koshaev, M. N. (1998). Socio-economic aspects of modern physical culture. Abstract. diss. cand. Science-Almaty, 29-64.

Mirzaee, A., \& Hasrati, M. (2014). The role of written formative feedback in inducing non-formal learning among masters students. Teaching in higher education, 19(5), 555-564.

Neiman, Yu. M. (1984). Models in Science and Technology. History, Theory and Practice (pp. 99-104). L.: Nauka, Leningrad.

Nyshanova, S. T., Baimukhanbetov, B. M., Abdugapparova, U. M., \& Mukhamedzhanov, B. K. (2014). Developing Future Teachers Creative Abilities In Competence-Oriented Educational Process of High School. 5th World Conference on Educational Sciences-WCES 2013. Procedia-Social and Behavioral Sciences, 116, 4287-4292.

Richmond, S. (2014). Towards Discursive Education, Philosophy, Technology, and Modern Education 
Philosophy of the social sciences, 44(5), 702-704.

Rienties, B., Luchoomun, D., \& Tempelaar, D. (2014). Academic and social integration of Master students: A cross-institutional comparison between Dutch and international students. Innovations in education and teaching international, 51(2), 130-141.

Rodzvilla, J. (2015). Modern Book Publishing: Web Sites for the Trade. Journal of scholarly publishing, 46(2), 158-174.

Stoliyarov, V. I. (1997). Spartian's games and clubs in the recreation, education and upbringing of children and youth. Center "Sparta" RGAFK.

Tanikeev, M. T. (1998). Theory and practice of mutual national factor in the development of physical education and sport in Kazakhstan. Almaty.

Uzakbaeva, S. A., Niyazova, G. Zh., Berdi, D. K., Baimukhanbetov, B. M., \& Seydakhmetov, E. E. (2013). The Introduction of Interactive Methods of Training of Forming of The Future Teachers. ${ }^{\text {rd }}$ World Conference On Innovation And Computer Sciences-INSODE-2013. AWER Procedia information Tehnology Comfuter Science, 4, 324-330.

Uzakbaeva, S., Baimukhanbetov, B., Berkimbaev, K., Mukhamedzhanov, B., \& Pralieva R. (2013). To the Problem of Forming Creative Competence of Future Teachers. Creative Education, 4(3), 234-240.

Yermentaeyeva, A., Turgunbayeva, B., Bazarbekova, R., Nurtayev, E., \& Bekzhanova, B. (2014). Specific features of masters students professional development. Conference: 5th World Conference on Educational Sciences (WCES) Location: Rome Sapienza Univ, Rome, ITALY Date: FEB 05-08, 2013 Book Series: Procedia Social and Behavioral Sciences, 116, 4764-4769.

\section{Copyrights}

Copyright for this article is retained by the author(s), with first publication rights granted to the journal.

This is an open-access article distributed under the terms and conditions of the Creative Commons Attribution license (http://creativecommons.org/licenses/by/3.0/). 